\title{
Social Housing in Algeria: Case Study of Batna City
}

\author{
Riadh Djafri, Mariana Mohamed Osman, Noor Suzilawati Binti Rabe, Syafiee Bin Shuid
}

\begin{abstract}
The housing crisis has become a major concern among Algerian citizens seeking a decent life. Low-and medium-income Algerians are facing this issue, despite various policies introduced by the state to ensure everyone is having access to housing provision. Based on the literature, majority of low- and medium-income Algerians are unable to own or buy a decent house, this leads them renting low-quality houses. The article aims to describe the current housing policies and the various housing programmes implemented in Algeria. An analysis on the architectural design of a sample of social housing units will also be discussed in this article. The findings of this research highlight the deficits, and the inferior quality of social housing in Batna city as a particular case study. Therefore, the collaboration of different stakeholders including government policies, architects and designers are needed for good quality social housing development.
\end{abstract}

Keyowrsd: Algerian social housing; housing policies and programmes; Algerian housing design.

\section{INTRODUCTION}

In the past couple of a couple of years, non-inexhaustible Social or subsidized housing in Algeria as the name suggested is affordable housing fully funded by the public fund through the Algeria Office of Promotion and Real Estate Management (OPGI). Most of these houses are being allocated for homeless families or families living in slums or squatter areas. The houses are built by the government and offer for rent at a minimal rate. Currently, the government of Algeria is working hard toward improving the overall housing conditions by targeting on the improvement in the quality of social or public housing in the country. The government also are constructing many social housing developments especially in the urban area where among many major issues are inadequate and low-quality social housing conditions of social housing units.

It is reported that, if the current conditions of housing in Algeria continue at the same pace, many problems will raise such as the inhabitable condition of the houses due to structural issues and low level of maintenance among these housing estates that can create urban slums within the cities [1]. As such, the housing crisis in Algeria not only

Revised Manuscript Received on April 19, 2019.

Riadh Djafri, Kulliyyah of Architecture and Environmental Design, International Islamic University Malaysia, Jalan Gombak, 53100 Kuala Lumpur, Malaysia. (Email: djafri.riadh@live.iium.edu.my)

Mariana Mohamed Osman, Kulliyyah of Architecture and Environmental Design, International Islamic University Malaysia, Jalan Gombak, 53100 Kuala Lumpur, Malaysia.

Noor Suzilawati Binti Rabe, Kulliyyah of Architecture and Environmental Design, International Islamic University Malaysia, Jalan Gombak, 53100 Kuala Lumpur, Malaysia.

Syafiee Bin Shuid, Kulliyyah of Architecture and Environmental Design, International Islamic University Malaysia, Jalan Gombak, 53100 Kuala Lumpur, Malaysia. problematic in term of quantity but also in term of quality and image to the cities. In addition, most of the houses that have been built did not meet the needs of Algerian society in most cases. Moreover, it is believed that Algeria does not have a clear and high-quality housing policy to achieve the need of its population [2], [3], [4]. It is argued that the houses built are not taking into account the collective behaviour of the inhabitants when designing these houses which lead to many social issues among the residents [5]. Various collaborative efforts among the government agencies are needed to ensure social houses are being built suitable to the residents. Unsurprisingly, Algerian cities are not included in the assessment of 100 cities with good quality of life as one of the criteria identified in this ranking is local living conditions based on housing condition [6].

\section{LITERATURE REVIEW}

According to the literature, Algeria is still facing an issue in the provision of houses and in responding to the current demand of all housing types especially to the low-income earners [7], [1]. The Algerian population growth is $1.9 \%$ per year with acute housing issues in the urban areas where the rural population is migrating to the urban areas to find better income and economic opportunity. This situation has created urban slums and overcrowding issues in many major Algeria's cities. Moreover, the rural-urban migration has led to the acute shortage of housing units in the urban areas, where approximately 4 million units needed in Algeria to overcome housing shortage by 2025 [5].

Currently, there are several types of housing programmes in Algeria plan for all levels of income (high-, middle- and low-income). The state considered that it is necessary to provide and facilitate the access to housing and solve the housing problems as this is the important element in providing the basic necessity and directly help to sustain good quality of life among the people [7], [8]. However, there is a lack of studies that have addressed the issues of social housing in the context of Algeria and Batna city particularly.

\section{Different housing programmes introduced in Algeria:}

As stated earlier, the government is still trying to eliminate precarious housing through the implementation and provision of social housing throughout Algeria to improve the living conditions and the overall quality of life. However, Algeria still has housing deficits, so if the 
situation continues at the same pace, many problems will be encountered such as transforming the structure due to poor urban planning and inappropriate housing supply. Furthermore, the housing shortage will, without doubt, lead increasing in slums, which have an impact on social problems with the uncontrolled overcrowding. This will influence directly the economy growth [1].

In addition, housing policy in Algeria is based mainly on the construction of a huge number of housing units of very low-cost rental and subsidised. In fact, the government is not able to respond to the current demand, in which the Algerian population growth is about 1.9 per cent per year with the high increasing urbanisation rate [7]. Indeed, the Ministry of Housing has created several types of housing programmes for all classes of society (high, middle and lowincome) in order to ease the crisis. It was reported that the demand for these programmes is far exceeded by supply, especially for low-income group. Thus, many efforts were done to overcome this crisis, nevertheless, it did not get a better result and the problem still ongoing [7].

Consequently, several reasons behind the housing crisis in Algeria; first, extended administrative process and mismanagement of funds over some project sites led to decrease the annual housing supplying from 165000 to less than 100000 units. In addition, several deficits have reported for the housing units under construction such as failure to respect the completion dates, unfulfilled commitments, the absence of technical inspection which directly influence the quality of housing. Second, limited land availability in some areas has largely contributed to restricting the growth of real estate market. In fact, the state is the primary owner of land in Algeria, and a very limited part is reachable to the private sector and developers. However, low supply has led to increasing the housing prices which went up beyond affordability, as a result, the rental prices are increasing. Third, the majority of households depend on public housing programmes and other strategies such as self-building on informally land and buying units in informal market. The massive price gaps between the private property market and affordable housing offered by the state have led to creating an informal or black market in which, many units of social housing are rapidly sold where ownership transfer is not officially registered. Finally, funding for the government's programmes was problematic in 2017, this is because of the state banks promised to pay US\$11 billion in 2013 in order to finance the housing programmes. Only US $\$ 1.38$ billion was paid between 2013 and 2015 and due to previous debts, which were not paid by the state banks. The foreign construction companies halted the works for several months which influenced significantly the delivery rate [7].

In Algeria, the main supplier of housing is the public sector. However, the contribution of the private sector has been increasing in the last two decades by offering a variety of housing with different mode of payment and procedures. The next part will discuss in details the programmes offered by each sector (See Appendix A).

\section{A. PUBLIC SECTOR:}

Public Rental Housing (LPL):

Public rental housing or better known as social housing is dedicated to the low-income and disadvantaged social groups who are homeless or living in precarious and unhealthy conditions. This type of housing is constructed by contractors assigned by OPGI under the ministry of housing. From 1979, the financing of social housing is $100 \%$ from the public funds with a repayment term of 40 years and interest of $1 \%$. It is occupied for a very low rental rate and managed by a specific legal regime [8].

The issue of access to social housing is evidently quite significant because it affects so many people's lives. Moreover, the supply of housing for none and low-income groups subject to special criteria. Furthermore, the typology of social housing has been changed during the last decades, in which the type of studio and F2 was eliminated and replaced by only F3 for a living area of about 67-meter square. This due to the inadequacy to the Algerian society and for improving the occupancy rate per unit and the quality of life condition as well.

\section{The Rural Housing Programme (LR):}

The objective for this type of housing is to fix the local population and promoting the rural areas. This by encouraging rural families to build in self-construction, decent housing in their own rural environment. Many advantages are introduced for this segment, practicing in rural areas can benefit from state aid for rural housing from 700000 to 1000000 DA (US\$6 390 - 9 128) from CNL (National Housing Fund) and a bank loan with interest rate is subsidized by the Public Treasury at 1\% [9].

\section{Lease to own programme (AADL):}

It is a new type introduced in 2001 in which, "AADL" is a mode of access to housing with a prior option for its acquisition in full ownership after a period of rental fixed under a given contract. According to the Official Journal [10], the price of units is fixed on the basis of the final cost of construction including land acquisition costs as well as technical and administrative management costs. However, the period of construction witnessed delayed despite the determination of duration of completion which was 18 months even though they are assigned to foreign companies due to financial problems as explained earlier. The conditions for AADL programme is that the applier has to pay $25 \%$ of the final cost of the housing unit, while $75 \%$ will be paid monthly during 25 years in which the beneficiary profit from a loan without interest and the state aid is fixed at 700000 DA for each beneficiary by the CNL [10].

\section{Promotional housing helped (LPA):}

It is a new housing type introduced in 2010 which is constructed by contractors, it is designated to postulants eligible to the state aid which belong to the medium-income group. The contractors benefit from 80 to $95 \%$ of land price reduction and the financing can be by personal contribution or enhanced credit $(1 \%)$. The beneficiary gets state aid of DZD 702000 (US\$6 400) from CNL when the income is greater than 1.4 times the National Minimum Wage 
Guaranteed (SNMG) and less than or equal to four (04) times the National Minimum Wage Guaranteed, and DZD 395000 (US\$3 600) when the income is greater than four (4) times and less than or equal to six (06) times the SNMG [8].

\section{Promotional Public Housing (LPP):}

This type of housing is intended for high-income segment, it is constructed by ENPI (The National Enterprise of Real Estate Development) which was created in 2009. Thus, promotional public housing is intended for citizens who are not eligible for social housing, LPA and AADL. This new housing formula is envisioned for citizens whose income is between 6 and 12 times the SNMG per month, which are also eligible for the subsidized credit of $3 \%$. It should be noted that the LPP housing units do not benefit from direct assistance from the CNL, as is the case for the LPA, LR or the AADL, but nevertheless benefit from the abatements on the land base [9].

\section{B. PRIVATE SECTOR:}

Promotional luxury housing "high standing" and promotional private housing:

Promotional luxury housing is introduced for the first time in 2000. It is basically intended for the rich category with pure commercial formula and does not benefit from any state aid. It is not subjected to any restrictions, budgets, areas or services. The purpose here is not to analyse its financing but the architectural production through the spatial organization of housing, materials, location in the city and comfort. These housing units characterised by more providing services such as lifts, underground parking, open space kitchen, permanent security [9]. According to Maya [11], the need to introduce and develop promotional housing standing and high standing would allow the qualitative improvement of other types of housing, particularly in terms of its quality by improving the living space, using new materials and enhancement of internal and external comfort. In addition, promotional private housing is carried out by private contractors with a variety of typologies and limited services compared to the high standing category.

\section{Self-built housing:}

Individual type assigned in subdivisions, of varied surfaces, to households of different standards of living. It is constructed and financed by the owner himself, or through a loan granted by the CNEP (National Fund for Saving and Reserve) at subsidized interest rates.

\section{Real estate cooperative housing:}

It is of collective type, semi collective or individual having the same characteristics as those of the promotional housing except for this one, the mission of project management is wholly assured by the owners [3].

From the foregoing, it can be inferred that Algerian national housing policy is still far from the reality to resolve the housing crisis, especially for social housing sector. Moreover, the objective of social housing is to accommodate the low-income category and eliminate precarious housing, slum, and shantytown. Thus, it appears that the current policy is not quite effective and needs to be improved. On the other hand, although the variety of national housing programmes in both public and private sectors and subsidies offered to all target groups, as well as the contribution of the CNL, it seems that the housing policy is taking a vicious cycle.

\section{METHODOLOGY}

The method used in this study is secondary data obtained from the department of housing in Batna city. In addition, a descriptive analysis through qualitative method of observation has been conducted for the case study of housing unit design. This allowed the researchers to provide an overview of the current housing policy and detail analysis on social housing design unit.

Case study research permit to investigate the phenomena from different aspects and faces in order to resolve the problem. Generally, in case studies, information can be obtained from different sources such as survey, interview, observation and analysis of document by employing quantitative, qualitative or mixed-method [12]. Moreover, case study is an analysis of persons, events, decisions, periods, projects, policies, or any kind of system which are studied using one or multiple methods. In this study, social housing units were selected to be analysed using observation tool, different statistics, architectural plans and photos from the case study were used for the analysis.

The selection of Batna city in Algeria as a case study was made based on several reasons. The first is the fact that a huge number of social housings have been constructing since 1975 (See Appendix B, Table 3). The second reason is the lack of academic research on social housing in Algeria and in Batna city in particular. The third reason is that Hamla town represents the most suitable case for the research objectives, as the location is built purely of collective housing with a considerable number of social housing constructed between 2003 till 2018.

Batna is an important East Algerian city, with an area of more than $12000 \mathrm{~km}^{2}$. According to the National Office of Statistics, it is ranked fifth in Algeria in terms of population, which reached more than 1.5 million in 2018. In addition, the construction of social housing in Banta city started in 1975 with the first programme. According to the Office of Promotion and Real Estate Management [13], Banta benefited from more than 57000 units, which have been constructing over the last decades.

\section{Selected social housing in Batna city:}

Hamla is a town located in Batna city, huge number of collective housings have been constructing since 2003. This including all type of housing units offered by the public sector in Algeria which comprise low, medium and highincome categories, i.e., Public Rental Housing, Lease to own programme, Promotional housing helped, Promotional Public Housing. In addition, social housing in Hamla town estimated to be about 5800 units distributed throughout Hamla 1, 2 and 3. Thus, the study focuses on social housing in these three areas (See Appendix B, Table 2). 


\section{ANALYSING SOCIAL HOUSING UNIT AT BATNA CITY IN ALGERIA}

This part will describe and analyse the design of social housing unit in Batna city, Algeria. The analysis will provide an overview of the interior and exterior layout from an organizational point of view, functionality, and standards of habitability in order to highlight the weak points of the design, which facilitate later the understanding of satisfaction and dissatisfaction of users. In addition, one of the objectives of post-occupational evaluation approach is the analysis of the design units. It is a step that called indicative evaluation [3].

Over the last decades, social housing units are subjected to ameliorations and evolutions. This can be shown in the typology and design by the changing of size, layout, and exterior of the unit. In addition, the amelioration was in terms of quantity by constructing social housing units. Moreover, the policy of providing social housing is still in progress in which 800,000 units planned to be delivered throughout Algeria by the end of the five-year period 20152019 [14]. While in terms of quality, in implementing and upgrading new construction materials and techniques. However, despite the considerable effort made by the government, the housing crisis is still raising many questions [15], [16], [2], [17], [18], [19], [20], [21], [8], [22], [23].

The majority of the social housing constructed in the last two decades are of typology F3. This is because the F2 type has ceased due to its poor design and small size as well as its inadequacy to the Algerian family. Thus, the size of social housing was upgraded to about 67-meter square per unit, while the total size is more than 75-meter square distributed according to the different types of rooms as mentioned in Appendix B, Table 1.

Most of the social housing blocks have five floors adjacent and only one single entrance for each block. In fact, the analysis is based on the spatial organization and layout, dimensions of the units, as well as the analysis of external spaces. Consequently, the analysis found that the layout and composition of different spaces are extremely limited for movement and manoeuvring. Careful site observation found that neighbourhood area is of inferior quality, with lack of open and green spaces and playground in most sites. The analysis also revealed that the interior design is poor and do not meet the requirements of technical standards for a quality living condition. Moreover, the enclosed design and lack of spaces such as balconies and loggias do not meet the needs for privacy and security. This was obvious with the changes and extensions in the exterior, interior design and facades made by the residents once occupied the housing units.

It can be concluded that architects did not take into consideration the sociocultural characteristics aspect of the residents. On the other hand, the designers are limited with the imposed standard, specification, and guidelines of social housing, which based on urban design, architectural design, function, and the structural aspect (constructive system adapted to the project). Thus, the plans of different typologies presented an element of deficiencies in the design as well as surfaces, spatial organisation, and exterior finishes as well. This will limit the function of users inside the housing units (See Appendix C).

To sum up, from the foregoing, it appears that the sociocultural aspect was marginalised during the design of social housing, so the identity and sociocultural practices considered as an inseparable part from the design steps, this for offering suitable housing units with decent quality which will lead to improving the quality of living condition of Algerian society. In addition, the injection of new techniques and materials will influence significantly and simultaneously the quality and the cost of construction.

\section{CONCLUSION}

After analysing and reviewing the social housing units and from the above discussion, in terms of housing policy, Algeria is working with various housing programmes to provide good quality housing for all Algerians. In addition, the different housing programmes offered in Algeria in both public and private sector coupled with specific financial mechanism to tackle various housing affordability issues. As such, access to excellent quality housing is important as this has a direct impact on Algerian's quality of life.

Based on the analysis, the housing quality is poor and inadequate to the Algerian society. The current housing policy has raised many discussions about the strategies adopted by the concerned authorities. Significant efforts need to be made to address the issues of shortage in social housing provision in Batna city and the rest of Algerian cities by formulating new housing strategies and plans to solve housing crisis. Therefore, addressing the lack, deficit, and the inferior quality of social housing in Algeria and Batna city In particular requires long-term thinking, purposefulness, radical changes and a strict political decision in improving the overall housing policy. Finally, both macro approach through government policies and micro approach with Algerian architects and designers are needed for good quality social housing development.

\section{APPENDIX A}

Recapitulative diagram of public and private housing presented in Algeria Source: Author, 2018

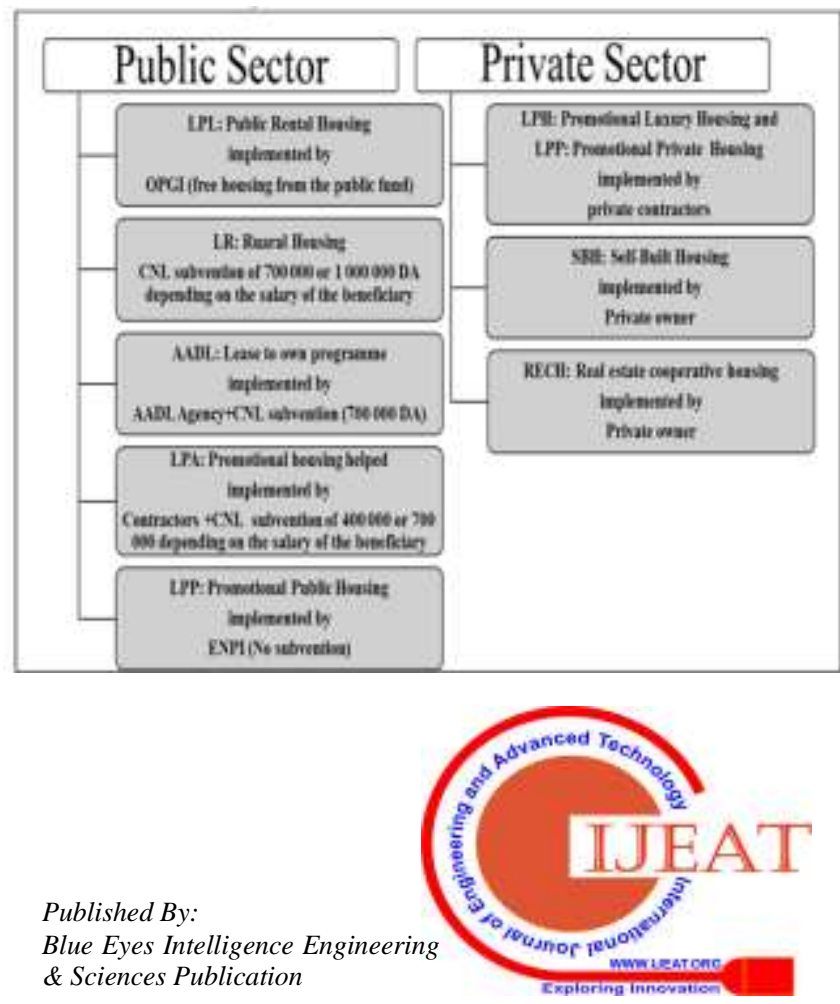




\section{APPENDIX B}

*Table 1: Social Housings Units' Surface Of Type F3

\section{Block of type F3}

\begin{tabular}{llc}
\hline Designation & \multicolumn{2}{c}{ Surface Sample (m2) } \\
model 1 & model 2 \\
\hline Living room & 21.06 & 20.02 \\
\hline Kitchen & 10.10 & 11.00 \\
\hline Bedroom1 & 12.50 & 12.00 \\
\hline Bedroom2 & 12.04 & 12.01 \\
\hline Lobby & 7.50 & 6.00 \\
\hline Bathroom & 3.60 & 3.51 \\
\hline WC & 1.50 & 1.60 \\
\hline Arrangement & 1.00 & 1.00 \\
\hline $\begin{array}{l}\text { Habitable } \\
\text { surface }\end{array}$ & $\mathbf{6 9 . 3 0}$ & $\mathbf{6 7 . 1 4}$ \\
\hline Laundry & 3.90 & 4.04 \\
\hline Loggia & 2.52 & 4.00 \\
\hline Total surface & $\mathbf{7 5 . 7 2}$ & $\mathbf{7 5 . 1 8}$ \\
\hline
\end{tabular}

*Table 2: Social housing units in Hamla town

\begin{tabular}{ccc}
\hline Localisation & $\begin{array}{c}\text { Housing } \\
\text { designation } \\
\text { (units) }\end{array}$ & $\begin{array}{c}\text { Program } \\
\text { (Launched) }\end{array}$ \\
\hline Hamla1 & 150 & 2005 \\
\hline Hamla1 & 450 & 2005 \\
\hline Hamla1 & 100 & 2006 \\
\hline Hamla1 & 140 & 2006 \\
\hline Total units & $\mathbf{8 4 0}$ & 2007 \\
\hline Hamla3 & 1600 & 2009 \\
\hline Hamla3 & 900 & 2010 \\
\hline Hamla3 & 800 & 2011 \\
\hline Hamla3 & 190 & 2011 \\
\hline Hamla3 & 200 & 2013 \\
\hline Hamla3 & 1180 & \\
\hline Total units & $\mathbf{4 8 7 0}(\mathbf{3 6 9 0}$ completed) \\
\hline Hamla2 & 90 & $\mathbf{9 0}$ \\
\hline Total units & $\mathbf{5 8 0 0}$ & \\
\hline Grand total & & \\
\hline
\end{tabular}


International Conference on Recents Advancements in Engineering and Technology (ICRAET-18) |15th and 16th March 2019|Siddhartha Institute of Technology \& Sciences, Telangana, India.

VIII. APPENDIX C

Different typical designs for social housing unit
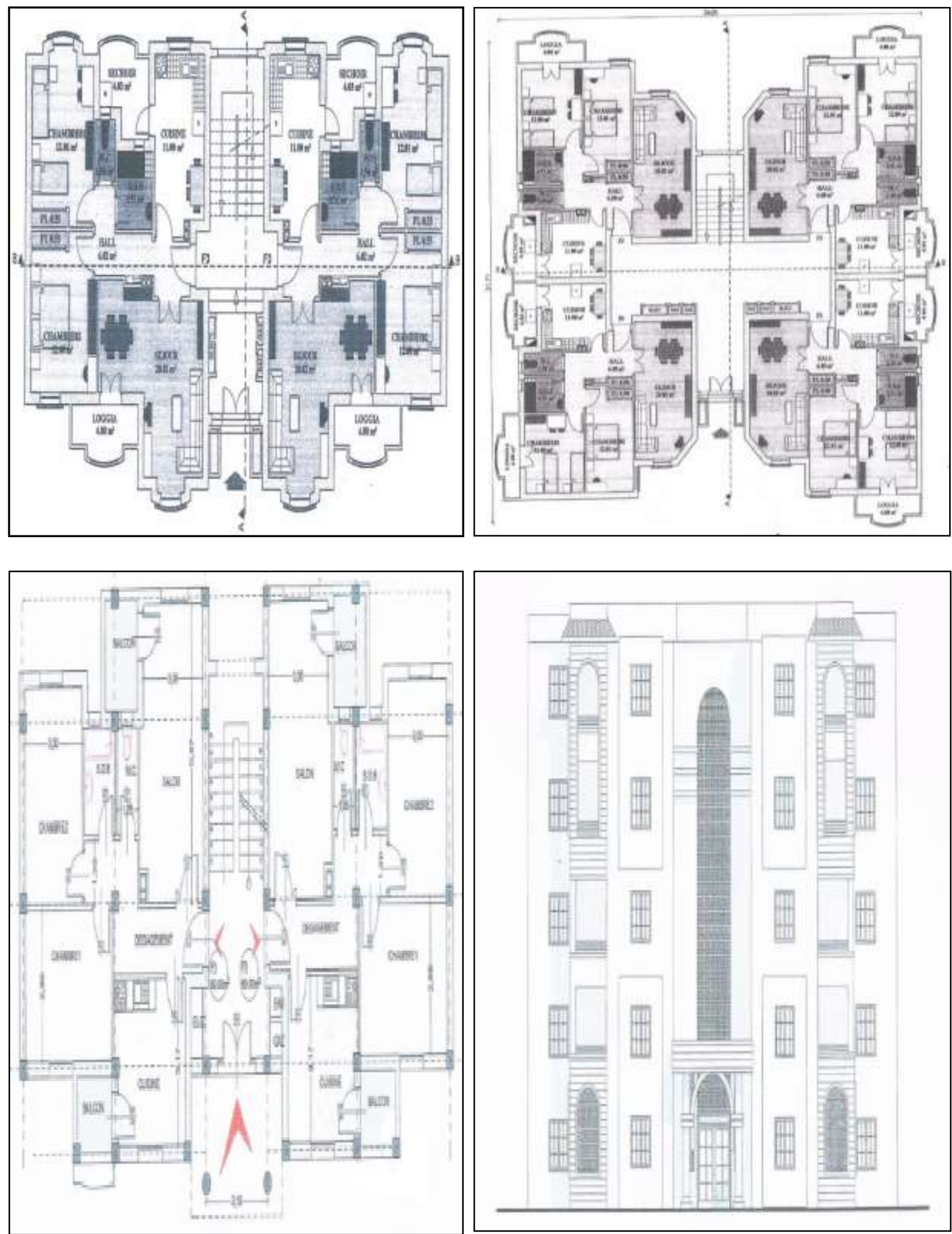

Source: Office of Promotion and Real Estate Management (2016) 


\section{ACKNOWLEDGEMENT}

A special acknowledgement to $\mathrm{mr}$ kadouri salah, head of study and realization service in office of promotion and real estate management (opgi) in batna city, for his precious support in terms of providing different documentations and facilitating the communication with other services.

\section{REFERENCES}

1. El-hadj, M. B., Faye, I., \& Geh, Z. F. (2018). Housing Market Dynamics in Africa (2018th ed.). London, United Kingdom: Palgrave Macmillan. https://doi.org/10.1057/978-1-137-59792-2

2. Bellal, T. (2009). Housing supply in Alegria: Affordability matters rather than availability. Theoretical and Empirical Researches in Urban Management, 4(3), 97-114.

3. Hadda, M. (2015). Le logement social collectif: Entre la conception et l'usage Cas de la ville de M'sila. Université Mohamed Khider - Biskra

4. Hamidou, R. (1989). Le logement : un défi. Entreprise Algérienne de presse.

5. Riad, T. (2016). La question du logement en Algerie. Les maximes existent toujours dans Le monde; il suffit de les appliquer!(pascal). مقاربات., 1(4), 424-437. Retrieved from

https://www.researchgate.net/publication/305319127

6. Mercer Human Resource Consulting. (2018). "Quality of living ranking 2018." Retrieved May 29, 2018, from http://www.mercer.com/qualityofliving

7. Centre for affordable housing finance in Africa. (2017). Housing Finance in Africa: A review of some of Africa's housing finance markets (8th ed.). South Africa: Centre for Affordable Housing Finance in Africa. Retrieved from

https://housingfinanceafrica.org/app/uploads/CAHF_sma llpdf.pdf?x77297

8. MHUV. (2018). Ministère de l'Habitat, de l'Urbanisme et de la Ville. Retrieved August 25, 2018, from http://www.mhuv.gov.dz/Pages/Article.aspx?a=79

9. Mouaziz-Bouchentouf, N. (2018). Histoire et politique de l'habitat en Algérie. Cours. université d'Oran. Retrieved from usto.dz/images/coursenligne/HPH.pdf

10. The Official Journal. (2016). The official journal / الجريدة 53 الرسمية, (65).

11. Maya, Urahli Radja. (2007). Le logement promotionnel en Algérie Entre 1, ordinaire et le standing Cas de la nouvelle ville Ali Mendjeli-Constantine. Universite de Constantine faculté de l'aménagement du territoire département d'architecture et d'urbanisme.

12. Priola, C. (2016). Understanding Different Research Perspectives. Retrieved from http://www.open.edu/openlearn/moneymanagement/understanding-different-researchperspectives/altformat-word

13. Office of Promotion and Real Estate Management (OPGI). (2016). Situation des permis de constructruire et assiètes foncière des programmes des logements sociaux. Batna, Algeria.

14. Ministère de l'Habitat de l'Urbanisme et de la Ville. (2015). Politiuqe gouvernementale dans le domaine de l'habitat, de l'hurbanisme et de la ville. Algiers.

15. Abdelkarim, H. (2012). Evolution des politiques de 1 ' habitat en algerie le L. S.P comme solution a la crise chronique du logement cas d', etude la ville de chelghoum laid. Université Ferhat Abbas Sétif, Algérie.

16. Behloul, M. (1991). Post occupancy evaluation of five story walk up dwellings : the case of four mass housing estates in Algiers. University of Sheffield.
17. Guendouz, T., Gasmi, S., \& Belhimer, I. (2017). The Five-Year Development Plans in Algeria 2001-2014. Unemployment and Inflation. Human and Social Studies "مجلة دراسات انسانية واجتماعية," 1892, 189-215.

18. Hadjri, K. (1992). Current Algerian housing policies affecting the methods for housing provision. Habitat International, 16(3), 71-78.

19. Lalonde, M. (2010). La crise du logement en Algérie: des politiques d'urbanisme mésadaptées. Université de Montréal.

20. Madani, S. Z. (2012). Le logement en algérie: programmes, enjeux et tensions. Confluences Méditerranée, 2(81), 133-152. https://doi.org/10.3917/come.081.0133

21. Mouaziz-bouchentouf, N. (2014). Le logement social à Oran . Conception, usages et ébauche $d$ ' évaluation. How to estimate the social housing after half a century of construction in Oran? Revue Géographique de l'Est, 54(3-4). Retrieved from url: http://rge.revues.org/5312

22. Saada, M. N. (1999). Housing Policy in Algeria. Issues and Perspectives, 1-14.

23. Semmoud, b. (1986). Politique d'haitat et acces au logement en algerie. L'exemple de l'oranie. In habitat, etat et societes au maghreb (editions c). Paris 